\title{
Preventing Injuries Via Innovative Investigations: Reviewing Dangerous Driving Research Methods
}

\author{
${ }^{1}$ Chris S. Dula, ${ }^{1}$ Russell Fox, ${ }^{1}$ Ashley Dickson, \\ ${ }^{1}$ Jessica Williamson and ${ }^{2}$ Fran Chumney \\ ${ }^{1}$ Department of Psychology, \\ East Tennessee State University, Johnson City, TN 37614-1702, USA \\ ${ }^{2}$ Department of Educational Psychology, \\ University of Nebraska-Lincoln, Lincoln, NE 68588-0345, USA
}

Received 2012-05-10, Revised 2012-05-15; Accepted 2012-07-09

\begin{abstract}
Dangerous driving behavior is particularly difficult to study for many reasons. Researchers must be creative to capture meaningful data, but innovative techniques often meet with problems that might be solved through the broader use by others. The researchers generally lack a central location from which to review and choose from past methods. This article reviews the techniques used to study driver behavior, particularly in the areas of aggressive and other types of dangerous driving. Problems in the literature are noted, including a lack of definitional consistency and the need for theoretical frameworks. While this presentation focuses primarily on problems in studying aggressive driving, the methods covered are more or less applicable to all manner of driver behavior issues, including risk-taking, drowsy driving, attention problems, training efficacy and age-related issues at both ends of the spectrum. This study disseminates information on a wide array of driver behavior study methods, including self-report, observation, simulation and instrumented vehicles and researchers a means to quickly review and choose from current approaches. Advancement in the field can depend upon the development of innovative methods of investigation and this study is meant to begin many conversations that can hopefully further such developments.
\end{abstract}

Keywords: Aggressive Driving, Dangerous Driving, Driver Research Methods, Driver Safety, Driver Study Techniques, Critical Analysis Reporting Environment (CARE)

\section{INTRODUCTION}

Motor vehicle crashes rank high among the most significant public health concerns today, as they are the leading cause of serious injury in US society and cause the most deaths for people ages 3-34 (CDCP, 2011; NHTSA, 2010). Annually, motor vehicle crashes bring about over 41,000 deaths, approximately 500,000 hospitalizations and 4,000,000 emergency room visits CDCP, 2003. In one year alone, the National Highway Traffic and Safety Administration (NHTSA, 2002) estimated the total economic cost of motor vehicle crashes to be $\$ 230.6$ billion due to medical expenses, lost productivity, property damage, legal costs.

The causes of crashes are myriad and it is critical we learn more about drivers in terms of attitudes, behaviors, emotions and cognitive processes. Alcohol use, speeding, red-light running, the lack of safety-belt use and the like, account for much of the damage. Alcohol use alone accounts for $22 \%$ of all crash costs, including $10 \%$ of all property damage costs, $21 \%$ of non-fatal injury costs and $46 \%$ of fatal injury costs (NHTSA, 2002). The remainder of the destruction comes from other dangerous driving behaviors.

Corresponding Author: Chris S. Dula, Department of Psychology, East Tennessee State University, Johnson City, TN 37614-1702, USA 
Relatively recently, the terms driver aggression and road rage have become increasingly familiar, reflected by public concerns on international roadways (James and Nahl, 2000). Drivers from not just the U.S., but from around the world as well, have reported that they are experiencing increases in encounters with angry and aggressive drivers (Deffenbacher, 2008). Reported that drivers high in trait anger are more likely to be angered by events on the road and become angry times more often than drivers who are considered to be low in anger. It was also noted that drivers considered high in anger exhibit approximately four times more aggressive behaviors and nearly twice the amount of risky driving behaviors as drivers low in trait anger. Shinar and Compton (2004) found that the most frequent aggressive behavior was cutting in front of another driver in a passing maneuver involving a lane shift. They found that this behavior occurred 4.3 times more than horn honking. They also found that honking was three times as common as cutting across multiple lanes and six times as common as passing on the shoulder of the road.

Aggressive driving is said to be responsible for extensive property damage, injury and death. Estimated that in 1996, 27,650 deaths, hundreds of thousands of injuries and roughly $\$ 50$ billion in crash-related costs resulted from aggressive driving on American roads. But, Martinez's definition of driver aggression was extremely broad, though not unusual and included behaviors such as speeding, red-light running and weaving in traffic, as well as acts actually intended to harm others. A common perception is drivers today are more aggressive than ever and that aggression is widespread and results in many crashes or near crashes.

Researchers concluded that many Washington, D.C. Beltway drivers felt crashes are frequently related to aggressive driving USDOT, 1998. Thirty-eight percent of a 1997 sample $(n=52)$ said driver aggression was one of three top causes of automobile crashes, compared to only $2 \%$ of a 1994 sample $(n=64)$. Participants in the 1997 sample were separated into a general driver group $(\mathrm{n}=32)$ and an aggressive driver group $(\mathrm{n}=20)$. General drivers identified driver aggression as a primary safety concern on the road and 53\% believed driver aggression was a main cause of crashes; contrasted with only $15 \%$ of aggressive drivers feeling this to be the state of affairs USDOT, 1998. Public uneasiness is also reflected in state legislative activity. Rathbone and Huckabee (1999) reported that in 1998, 9 states introduced 26 bills targeting aggressive driving. So far, at least 33 states have enacted laws and/or started enforcement programs aimed at reducing aggressive driving and road rage (NHTSA, 2001).

Typing in "aggressive driving" and "road rage" as unified search terms on a common Internet search engine (see http://www.google.com/) revealed 300,000 hits and $3,440,000$ hits, respectively, in May 2009. This is an increase from 21,100 and 173,000, respectively, on the same search engine in February 2003, as cited in Dula and Geller (2004). Though considerable redundancy certainly exists between sites and web pages, there is an immense amount of public concern regarding these topics. In contrast, the same search terms used on a common psychology journal database (PsycINFO) yielded 155 works pertaining to aggressive driving and 80 referring to road rage (up from 29 and 18, respectively, on the same database in February 2003; Dula and Geller, 2004). Given the public perception of the problem, the amount of scientific research dedicated to the issues seems modest. Historically, aggressive driving has been a label applied to all manner of dangerous and discourteous driving, while road rage has been used typically for more clearly aggressive actions, though not consistently (Dula and Geller, 2004). Whether unsafe lane changing, horn honking, speeding, red light running, are actual aggressive behaviors, is a matter of some debate.

\subsection{Conceptual Issues}

Controlled and systematic studies cannot be accomplished without clarity of concepts. While there is a noted lack of research (Dula and Geller, 2004; Gulian et al., 1989; Tasca, 2000), there is also agreement regarding the need for a consistent definition of aggressive driving (Dula and Geller, 2004; EllisonPotter et al., 2001; Lonero, 2000; Sarkar et al., 2000; Tasca, 2000). The expressions "road rage" and "aggressive driving" are sometimes used interchangeably and sometimes distinctly. While this is to be expected in laity, more rigor is called for with regard to psychologists and other social scientists labeling and studying aggressive behavior in a vehicular context.

Rathbone and Huckabee (1999) concluded that definitions of road rage vary dramatically and are often vague or lacking altogether, but they also emphasized that road rage and aggressive driving are not one and the same. Tasca (2000) discouraged the use of the term "road rage," while Dula and Geller (2004) recommended that "road rage" be eliminated from the scientific literature as it is defined inconsistently, difficult to define operationally and is more a colloquial than a scientific term. In contrast, aggression is a concept with a rich literature base and has 
been studied in many contexts with a great deal of theoretical grounding.

Road rage as a concept has no theoretical grounding and lacks a history of empirical research and consistency of usage. Aggressive driving also has a short empirical history and definitions have been varied and inconsistent. Dula and Geller (2004) for a review of aggressive driving definitions found in the literature to date. Intention to harm, however spontaneous, is crucial in defining aggression in any context (Felson et al., 2000). Incorporating elements of reasonably acceptable definitions (Ellison-Potter et al., 2001; Lajunen et al., 1998; Tasca, 2000), Dula and Geller (2004) offered the following: "Aggressive driving is any behavior emitted by a driver while driving, that is intended to cause physical and/or psychological harm to any sentient being." (p. 565). Additionally, three categories of driving have historically been labeled as aggressive in the literature: (a) intentional acts of physical, verbal, or gestured aggression; (b) negative emotions (e.g., anger, frustration) while driving; and (c) risk-taking (Dula and Ballard, 2003; Dula and Geller, 2004). Proposed using an all encompassing behavioral spectrum called dangerous driving where the two categories of risky driving and negative emotions while driving are studied as elements of aggressive driving when and only when, they are actually associated with aggression (i.e., behavior intended to harm).

With regard to risky driving, weaving in and out of traffic, running red lights, speeding and the like are dangerous behaviors, but without intent to harm another person either psychologically or physically, they are not aggressive in nature and should not be labeled as such. Risky driving also includes the use of cellular phones, eating, drinking, reading and grooming while driving, driving under the influence of a substance, drowsy driving and failure to wear a safety belt. With regard to negative emotions, one can get angry at another driver or at another person in a vehicle, but not express this anger in an aggressive manner. Driving when one is angry or otherwise upset is dangerous because it diverts cognitive resources from driving, but unless directly tied to an expression of hostility, it is not indicative of aggressive driving. Theoretically, even driving in the presence of a strong positive emotion may pose a similar distractive danger.

Lourens (1990) cited a need for development of theoretical models of driver action and noted it would require taking into account cognitive/information processing, motivaitonal, intentional and emotional factors. Dula et al. (2011) developed a social-cognitive theory of driver aggression. With such a model, the roles of situation and personality traits are considered in regard to the occurrence of aggression in a driving context. The model, as yet untested, is only one of several plausible models for studying driver aggression. Similarly, research on other types of dangerous driving should be grounded in related theory.

Geller (1998) attempted to call attention to how behavior analysis could be applied across a wide spectrum of safety factors to prevent crash-related injuries. Further, an efficient behavior-based approach was explicated by Dula and Geller (2007) to inform the development of a Total Traffic Safety Culture. The theory of planned behavior along with other theories have beeen used to predict motorcylclist speeding (Chen and Chen, 2011; Elliott, 2010) and work-related driving behaviors (Poulter et al., 2008; Wills et al., 2009). Social integration and control theories have predicted male motor vehichle crash-related mortality (Kposowa and Breault, 2009). Also, general strain theory has been employed to predict delinquent/criminal responses by younger drivers (Ellwanger, 2007). And, a broad sociological theory has been utilized to predict differences in group-based (e.g., national, sex, age) driver collisions in terms of driver interactions (Factor et al., 2007). Yet, as is likely obvious, a systematic and consistent application of theory is lacking overall.

A separation of assorted elements previously labeled as aggressive driving or road rage should prompt an increase in empirical study. Thus, dangerous driving of all types should be studied with relative independence so as to reduce confusion amongst similar, but separate, topics. Use of operational definitions should also create a common language that will enhance the transmission of information within the field. As more relevant, theorydriven research emerges, advances in methods for measuring conceptual elements should be expected.

Hypotheses need to take account of such predictors as driving conditions, driver states, driver history and traits, driver responses, interactions of responses and perceptions between drivers and the like. Given that conceptual issues need to be addressed, the pressing questions become those of which methods should be employed. Techniques used to study dangerous driving behavior are numerous, but their applicability varies considerably when it comes to studying the complicated aspects of driving. Thus, we turn to a critique of current research techniques.

\subsection{Research Techniques}

According to Tasca (2000), the available research on aggressive driving can be categorized into two main groups: (1) surveys of the driving public and, (2) small- 
scale field experiments involving select samples of drivers. Due to definitional inconsistency in some studies, the value of much of the research conducted to date is questionable. At the least, some of the studies to date serve as pilots for future study. Indeed, future study can be better informed from previous research and designed so as to produce more reliable (i.e., replicable) and valid results. Dula and Geller (2004) propose the use of social cognitive theory will help in generating testable hypotheses, big issues remain as to how to reliably and validly measure traits and situational factors so as to shed light on the causes and maintenance factors of aggressive and dangerous driving.

\subsection{Self-Report Measures}

Self-report measures have been used extensively in the research on aggressive driving and other types of dangerous driving and are likely to be continually used until more objective methods are developed. In driving research, as is the case in most research based on recall self-report, the main difficulties are the long known facts that participants tend to reconstruct memories inaccurately (Loftus, 1974; 2003) and that they often react with a positive self-presentation bias (Crowne and Marlow, 1960; Marlow and Crowne, 1961). It was noted early on in the aggressive driving literature that participants may consciously present themselves in a favorable light and that measurement itself may affect participants in such a way as to elicit these types of presentations (Doob and Gross, 1968). It is also important to note that the most risky drivers are more likely to underreport their risky driving behavior (Nevitt and Lundak, 2005). Additionally, in questions of intended behavior, people often cannot truly know what they would really do in an actual situation without having been in a similar situation. Self report measures have been criticized as being very limited in their ability to predict actual driving outcomes (Houston et al., 2006).

In a questionnaire, Doob and Gross (1968) asked college students what their response would be to an unresponsive vehicle blocking them at a green light. On average, males said they would be quicker to honk at a car of higher social status, while females said they would be quicker to honk at a low-status car. In their classic field experiment, covertly recorded behaviors showed both genders were slower to honk at high-status cars (Doob and Gross, 1968). Still, behaviors estimated on the self-report measures and those recorded of drivers were not extremely dissimilar. For instance, the average actual high-status honking latency for males was $8.5 \mathrm{sec}$ while the mean estimated honking latency was $5.5 \mathrm{sec}$; a difference of only $3 \mathrm{sec}$. Differences between estimated and actual behaviors were not as big as this in other conditions (Doob and Gross, 1968). Nevertheless, precision is obviously a highly desirable quality in measurement.

\subsection{Social Desirability Bias}

Empirically sound self-report measures of dangerous driving behavior are necessary for research (e.g., to understand differences between driver aggression and purely risky driving) and for applied uses (e.g., clinical assessment and intervention, employment screening). As mentioned however, a dilemma with self-report measures is that people tend to answer items in a manner that reflects a social desirability bias. In a study of relations between trait anger, trait aggression and aggressive driving, the Dula Dangerous Driving Index (DDDI; Dula and Ballard, 2003) was used to measure varying levels of aggressive, negative emotional and risky driving the Propensity for Angry Driving Scale (PADS; DePasquale et al., 2001) was used as an assessment of driver anger levels. Significant correlations were found between the DDDI, the PADS and the Interpersonal Behavior Survey's Denial scale (IBS; Mauger and Adkinson, 1980). Furthermore, the IBS Denial scale accounted for significant variance in DDDI scores. It was clear the more one denied the presence of minor flaws and faults, the more one reported lower levels of aggressive driving and risky driving. Thus, the data indicated social desirability biases were in operation, affecting participants' willingness and/or ability to report higher levels of driver aggression and risky driving.

Recognizing this issue, researchers created the Driver Social Desirability Scale to gauge impression management in relation to driving and to measure one's tendency toward self-deception regarding negative personal characteristics (Lajunen et al., 1997). Their research suggested a driver-focused measure of social desirability was more appropriate for driving research than traditional social desirability measures. As the problem of socially desirable responding is common, the development and use of social desirability inventories allows for some control of this variable's influence. While not a perfect solution, many aggressive driving researchers using self-report inventories have not even bothered to address this problem. Studies examining alternative methods, such as implicit association tasks, have shown some promise in minimizing the effects of social desirability but still need further research (Hatfield et al., 2008). 


\subsection{Phone Surveys}

Situational cues and behaviors must be perceived and interpreted before influencing a driver's actions. Thus, it's critical to understand what types of driving circumstances are considered aggressive by drivers in general. The use of phone surveys has been helpful in delineating the prevalence rates of certain behaviors and in determining what acts drivers believe are aggressive acts CSCSA, 2001 (Joint, 1995; NHTSA, 1998). Phone surveys have contributed to the understanding of the popular conceptualization of aggressive and other types of dangerous driving.

To contribute further to the literature, the scope of future phone surveys must be expanded. It is no longer enough to ask whether one has been the victim or perpetrator of aggressive driving, or how big a problem they feel aggressive driving is in their community. It's important to study the self-reported precipitating factors for aggressive driving behaviors. Thus, variables such as time constraint, mood, level of driving skill, traffic and weather conditions and contextual interpretations, must be queried to gauge what conditions are more likely to precipitate aggressive driving.

With this approach, phone surveys can produce new practical knowledge. However, lengthening the protocol of phone surveys may jeopardize their validity. Since drivers who are not compensated for their time and effort should have little motivation to participate earnestly in a lengthy survey, they may give flippant or unconsidered answers unless they have particularly strong views to air.

A final issue is the ever-present specter of selfselection, as phone surveys must take particular precautions to ensure they reach a representative sample. A survey given at only particular points during the day or to low numbers of participants will generate a limited sub-sample. Also, surveys without proper introductions risk instantaneous refusal, though with proper design, refusal rates can be diminished. This can be done by assuring potential respondents immediately that the call is not a sales call (made somewhat easier now with the "no call" list maintained by the federal government), the study is important to science, their responses are likewise important, their responses will be anonymous and that the time taken will not be excessive.

\subsection{Mail-in Surveys}

In the past, mail-in surveys have also been used with some success (Lajunen and Parker, 2001; Parker et al., 1998; Rathbone and Huckabee, 1999; Stradling and Meadows, 2000). With these surveys a major dilemma is once more, self-selection of respondents into the sample. While this problem is not unlike those in other areas of psychological research, mailing participants are again not typically compensated. Thus, those who complete and mail back surveys without compensation are most likely to be those individuals with particularly strong views on the topic.

In cases where there is compensation, it is impossible to tell if responses are genuine or part of a random or acquiescent response set. The longer the survey, the more likely participants will engage in quick responding without taking time to diligently read and respond to the items. Also, it is impossible to tell if the information came strictly from the participant or if the responses were the product of a conversation the participant had with one or more other people while filling out the survey. Moreover, where items are ambiguous, there is no one the participant can ask to gain clarification. Obviously, there are advantages to be had by mailing surveys versus administering them in group settings; however, there are advantages to the latter as well.

In group settings the survey is completed by one person in the presence of a group monitor. In a group situation, the contingencies and expectations for participant behaviors are clearly defined and/or implied. And, a group monitor can provide answers to specific on-the-spot questions. Additionally in the group context, there is an explicit effort on the part of both the participants and researchers to be present, which would presumably arouse cognitive dissonance in participants who may otherwise choose not to conform to expectations. However, none of this guarantees participants in a monitored group setting will fill out measures completely, honestly and without a social desirability bias. Thus, the mail-in variety of survey completion is probably no less valid on the whole.

As a final issue, response rates are generally low to mail-in surveys. Response rates are important in terms of statistical power, sampling error and generalizability (Gore-Felton et al., 2002) and increasing response rates should be an important consideration in designing any mail-based research. Through proper design such as the use of a pre-survey introductory letter, post-survey follow-up reminders and modest monetary incentives, response rates can be brought to reasonable levels (Erwin and Wheelright, 2002; Gore-Felton et al., 2002; Helgeson et al., 2002; Oden and Price, 1999). Highquality design can even bring up response rates for males, who are traditionally more reluctant mailing participants than females, in dealing with sensitive topics 
(Senn et al., 2000). Also, Kenhove et al. (2002) reported that topics where participants perceive they are highly involved produce higher response rates. One would think high-involvement applies to many driving situations, but perhaps the effect is lessened where social desirability is highly aroused.

\subsection{Driving Diaries and Checklists}

One unique approach in the self-report realm is the driving diary whereby drivers maintain systematic records of daily driving experiences (Underwood et al., 1999). There are a number of ways to approach this concept, including narrative journal entries, short answer responding to pre-determined prompts and filling out checklists. Recording events immediately after they occur should theoretically ensure a much higher rate of accuracy, as opposed to having drivers estimate behaviors out of context after variable intervals have passed between experience and query. With this method, drivers can be compensated for their efforts and prompted as frequently as needed to remind them to make entries on a regular basis. However, there is of course, no guarantee they will do so and some studies implementing driving diaries as a method of measurement have reported low or inconsistent rates of compliance (Millar, 2007; Underwood et al., 1999).

Writing narrative journal accounts seems to be the least desirable form of this approach for a number of reasons. On the researcher's side, one depends on participants' writing to be legible and their entries to be accurate representations of full trips. Entries must then be categorized into quantitative data, which is time consuming and brings in the issue of inter-rater reliability for coding. On the participant's side, writing full entries at the end of trips might be tedious and frustrate immediate goals to be somewhere at a specific time.

A similar approach that should eliminate these concerns to a large degree is to have drivers fill out reasonably short checklists. Critical behavior checklists have been developed and used in a variety of industrial safety applications (Geller et al., 2002; Williams and Geller, 2000). Geller (1996) developed a Critical Behavior Checklist for Driving for use in teen or novice driver training, which could be adapted to a variety of uses in driver self-monitoring. Checklists can be created to cover many variables and they are quick to fill out as one only needs to check off or tally the relevant behavioral or experiential categories for each trip. Continued use of a particula checklist format should further speed the process as one becomes familiar with the layout and categories.
Drivers can be formally trained on the use of a checklist before going into the field, so they become more aware of the need to be objective and diligent in observing and recording their behavior. Additionally, participants can be prompted by mail, e-mail and/or phone calls, to increase the likelihood they will fill out checklists on a regular basis. But, of course, this does not guarantee they will do so. Even with proper checklist design, there is some chance of losing the richness of data provided in the journal entry method, but this could be remedied by a hybrid approach whereby drivers have space to elaborate on particular driving events when salient and/or have specific prompts to address in short answer form.

\subsection{Driving History and Records}

When studying driver aggression and risky driving, it would be helpful to have an objective history of participants' driving violations and crashes. With self-report research, one usually does not have the ability to independently verify their participants' responses to questions. Retrospective reports are often requested without cues a driver could use to retrieve a reasonably accurate memory of the instances and circumstances surrounding a variety of driving events. Having noted the problems of memory and selfpresentation biases inherent in self-report measures of driving behavior, it behooves researchers to consider obtaining permission to use participants' driving records, available either through the Department of Motor Vehicles or insurance companies.

Surprisingly few studies consulted motor vehicle records as data sources. Researchers who have used this archived data have studied such varied topics as: (a) the application of driver interlock systems as an intervention to reduce Driving Under the Influence (DUI) (DeYoung, 2002; Marques et al., 2003), (b) the effects of head trauma on driving behavior (Schultheis et al., 2002), (c) DUI offender recidivism (Cavaiola et al., 2007; Cherpitel and Bond, 2003; Ferrante et al., 2001; Marowitz, 1998), (d) the impact of sending warning letters to risky drivers on future infractions (Jones, 1997) and (e) to compare parents' driving records to their teenagers' driving record (Ferguson et al., 2001; Wilson et al., 2006).

Driving records were used to see if individuals with previous ticketed offenses or reported crashes are at a greater risk for future offenses and crashes (Elliot et al., 2000). Elliot et al. (2000) found that in the early stages of drivig, offenses and crashes are often attributed to inexperience and are therefore characteristic of many beginning drivers. 
Parents with poor driving records are more likely to have kids with poor driving habits (Ferguson et al., 2001). Ferguson et al. (2001) and his colleagues found that in both single and two-parent homes, parents' driving records were predictive of their children's records. Since it is known that parents have this influence over teenagers' driving, we should take this into account and parents should model good driving behaviors around their children. Both mothers and fathers influenced children's driving (Wilson et al., 2006). The results confirmed and extended the findings of Ferguson et al. (2001) that youth collision risk is related to both parental collisions and offenses (Wilson et al., 2006). Wilson and his associates considered that there may also be an association between parents' driving and parenting practices. Wilson and his colleagues stated that parenting practices are related to youth driving risk (Shope et al., 2001) so one reasonable hypothesis is that parents with bad driving habits also provide lower nurturing and monitoring of their children (2006).

Seventy-seven individuals convicted of drinking and driving (DUI) offense were screened for recidivism approximately 12 years following the first offence (Cavaiola et al., 2007). Driving records were used from the time of first arrest for DUI and at follow-up. The results indicated that, among recidivists, an average 6 years elapsed between 1 st and 2nd DUI offenses (Cavaiola et al., 2007). In another study, driving records and self-report measures were used in combination. Driving records were examined to see if there was an association between alcohol/drug abuse diagnoses, driving convictions and trait risk-taking among drivers admitted to a trauma center (Soderstrom et al., 2001). It was found that patients without substance use disorders and those who had no convictions, were less prone to dispositional risk taking than those who had such disorders and/or convictions. Use of self-report measures with more objective driving records has the added value of linking personality constructs to meaningful and relevant behavioral outcomes.

In many, if not most states, driver records are considered public information and may be accessed by anyone who is willing to pay for them. Thus, one only needs participant permission to obtain such records in conjunction with a study involving said participant. While not as convenient as taking a participant's word at face value, it is likely worth the effort and expense to obtain objective evidence of dangerous driving behavior and crashes. Costs for accessing driving records vary from state to state and thus it may be relatively expensive to get data from a large representative sample. For instance, Iowa currently charges $\$ 5.50$ for a copy of a certified driving record, whereas New Jersey charges $\$ 10$ (NJMVC, 2009). In some cases, collaboration between researchers and law enforcement or insurance agencies might diminish expenses.

The largest problem with this approach is that actual instances of being caught driving dangerously are much fewer than actually occur on a regular basis, as infractions generally come from a small sample of driver behavior. Also, crashes are relatively infrequent events where official and accurate attributions of driver fault and reasons for fault may or may not be listed. Moreover, a significant minority of injury-producing crashes are not reported to the police. In 2000, it was estimated that approximately 11.3 million vehicles were damaged in non-police reported property-damage-only crashes (NHTSA, 2002). The property-damage-only crash is the most common type and is certainly an important indicator dangerous driving.

As crashes do not necessarily show up on police records, they are even less likely to appear on insurance records. While the police have records of all cited motor vehicle infractions, such incidents are not usually automatically reported to insurance companies. Therefore, insurance records are likely a less reliable source of dangerous driving data than the former. Also, states and insurance companies vary in how long they maintain infraction and crash data on a driver's record. Nonetheless, data from these sources is likely to be highly accurate and relatively unbiased, if underreported.

Additionally, many states now maintain official crash databases which have a wealth of information to offer regarding various aspects of dangerous driving. This type of archival records research points to trends that occur on our roadways. For example, the Critical Analysis Reporting Environment (CARE) is a data analysis software package designed for traffic safety problem identification and countermeasure development. Dr. David Brown originally developed the program at the University of Alabama and it has been adapted for use with various states' crash data. CARE is utilized to analyze crash data to identify crash problems, trends and profiles throughout a state (for more details, see http://care.cs.ua.edu/default.aspx).

However, where states do maintain accessible databases, the limiting factor is the time delay in the transfer of data from various state agencies into the central database. In most cases, the most recent data is at least two years old. The Fatality Analysis Reporting System (FARS) which contains data on fatal crashes, is maintained by NHTSA is one of the most up to date databases being only one and a half years behind the 
current date (for more details, see http://wwwfars.nhtsa.dot.gov/). However, as technology is advancing at a rapid pace, state and federal agencies should make speeding up the process of data transfer a high priority. Thus, there should be a push to update data transfer technology and to get all states involved in such crash data initiatives.

\subsection{Observing Real-World Driving Behaviors}

Tasca (2000) concluded that research using actual observation of aggressive driving on roadways was virtually non-existent and suggested that systematic realworld studies are needed to improve our understanding of aggressive driving. This is certainly the case with all forms of dangerous driving, but unfortunately, is easier said than done. Random drivers observations suffer from the inability of the researcher to know specifics about the driver in question, other than what might be inferred from vehicle movement (e.g., turning without signaling, red-light running) and possibly knowledge gained from a quick glimpse of the driver (e.g., displays of gestured aggression, gender, cellular phone use). License plate data would not provide much useful information as the driver of any particular vehicle is not necessarily its owner. To avoid influencing the behavior of the observed drivers, observation posts would need to be inconspicuous, which may be difficult to accomplish in some areas. Still, a small number of quasi-experimental field experiments have successfully applied in vivo observation procedures (Ludwig and Geller, 1999).

\subsection{Direct Observation}

To date, small-scale field experiments have contributed little to our knowledge of aggressive driving, as most have to do with horn-honking. Basically, all we know from such studies is that some people will honk at a vehicle in front of them if it does not respond promptly to a green signal, where others will passively sit and wait for the vehicle to move and if the vehicle is not equipped with an air conditioner, drivers are even more likely to honk when the ambient temperature is high (Doob and Gross, 1968). While this is somewhat helpful information when trying to understand the causes and maintenance factors underlying aggressive driving, it is very limited and illustrative of the problems in operationally defining aggression in a driving context.

Obviously, there are problems with the operational definition of horn-honking as aggression. Horn-honking may be an aggressive act, but only when the honker intends to scare, embarrass, or annoy the target. Hornhonking can also be a more or less friendly signal intended to help the unresponsive person refocus on the road. The problem is that intention is impossible to assess from hearing a horn, unless it is repeated excessively or accompanied by obscene gestures.

Beyond aggressive driving per se, researchers have successfully observed other real-world dangerous driving behaviors, resulting in the accumulation of reliable and valid data. In testing interventions designed to increase safety-related driving behaviors, Ludwig and Geller (1997; 1999) observed the behavior of pizza delivery drivers during peak business hours. This was done by recording data unobtrusively from windows of nearby businesses which overlooked the pizza businesses' parking lots. Observers were trained to use a checklist to record whether deliverers (identified by license-plate number) used their safety belts, used their turn signal and made a complete stop before entering the roadway. Interobserver reliability data were intermittently collected by having two observers record concurrently, but independently (Ludwig and Geller, 1997). A large amount of data can be collected in this manner, as demonstrated in Ludwig and Geller (1999) study where 5,711 vehicle observations were recorded on 60 different deliverers over 13 weeks.

\subsection{Cellular Phones}

An innovative field-study method is the provision of visor-mounted cellular telephones with which researchers call to obtain ongoing observations from participants while they are driving (Hennessy and Wiesenthal, 1999). In this study, researchers were primarily interested in the effects of traffic congestion and they called participants on a single trip and administered a structured interview that measured driver state stress and driving behaviors. Prior to the in-car cell phone interview, participants completed a self-report measure to gauge levels of driver trait stress. The authors noted some problems with the design, including the fact that data were only collected on one trip per participant and thus complex behavioral patterns may have been missed due to a lack of variance in situational variables. Another potential problem was the forced-choice nature of answers. It was suggested that open-ended questions might be more useful in the future and would allow for the recording of a wider array of behavioral outcomes (Hennessy and Wiesenthal, 1999).

The use of cell phones has great potential in assessing ongoing driver behavior as a function of numerous independent real-world variables. Safety in using this technique would be a primary concern, in that drivers should not actually be driving at the time the 
interviews are conducted. However, with proper design, instruction and contingency structuring, this should be a relatively achievable safety goal.

Another phone-related method of studying real-world driving behavior is to analyze police and/or emergency response calls. For example, researchers examined cellular phone calls to the California Highway Patrol from freeways in San Diego over a three-month period (Sarkar et al., 2000). Analyzing a total of 1,987 calls, they placed each into 1 of 5 different categories. They found $19.8 \%$ of calls referred to drivers speeding excessively; $24.6 \%$ were related to drivers combining speeding with at least one other at-risk behavior; $27.1 \%$ referred to drivers weaving in and out of traffic and cutting off other vehicles, but who were not speeding (usually in heavy traffic); $12.5 \%$ dealt with drivers tailgating; and, $16.1 \%$ were about drivers who were perpetrating various types of road rage. In the road-rage category, the listed behaviors were almost invariably aggressive in a classic sense, given that an intention to cause physical and/or psychological injury to the target was clearly implied (Sarkar et al., 2000).

While this is an innovative method of study, it has some limitations in that the behaviors must be categorized subjectively without direct contact with the caller. Also, calls are from the point of view of an observer and not the offender. Thus, it appears the data collected in this manner can only be epidemiological. Nonetheless, it may be possible to develop different protocols and collect data in a way that enables researchers to verify behavior reasonably well and to categorize independent variables such as weather conditions and traffic density, as well as effects of the target behavior.

\subsection{Video Observation}

Video-recording of driver behavior is an option that does not appear to have been used extensively beyond simulated driving and responses to driving videos. Generally this should not be a problem from a legal standpoint as driving is a public behavior. Video data has the advantage of increased observer reliability as one can zoom in on an image, pause it and/or run it in slow motion. With real-world observations recorded by hand, data can never be reviewed for reliability. This issue is often addressed with two data collectors recording the same variables concurrently and independently and then computing a reliability index. However, reliability data generally only covers a small percentage of a total data set and veracity and/or accuracy can never be doublechecked to pinpoint the source of discrepancies. While it is tedious and time consuming to code video data into meaningful behavioral categories, it is not significantly more difficult than coding it first-hand and the data can be viewed by multiple observers as often as needed.

With dangerous driving behaviors such as red light running, failure to signal, failure to use a safety belt, weaving, the general frequency of these behaviors would allow for recording a significant number of instances during almost any reasonably long observation cycle. However, the capturing of the relatively infrequent aggressive driving behaviors would be limited by camera location and having to sift through hours of tape to code significant instances of behavior. Drawbacks aside, this seems a technique ripe for experimentation in the field, especially as technology makes the recording and storage of video data simpler and more practical.

\subsection{Instrumented Vehicles}

A final technologically-advanced method of studying real-world driving behavior is the use of an instrumented vehicle, which does incorporate video technology. For instance, Boyce and Geller $(2002 ; 2001)$ used such a vehicle to obtain behavioral data from 61 drivers ranging in age from 18-82, to study the impact of various individual differences (e.g., gender, age) on dangerous driving behaviors. To reduce participant bias, they attempted to hide the true purpose of the study from participants by billing it as an evaluation of cognitive mapping and way-finding abilities. Such research stands in stark contrast to earlier driver investigations which relied heavily on self-reported data.

The instrumented vehicle used by Boyce and Geller was a 1995 Oldsmobile Aurora with an exterior and interior no different than a standard private vehicle. The vehicle was capable of unobtrusive video monitoring using four concealed cameras, each the size of a pin head. The driver's face and hands were videotaped, as were the areas in front and back of the vehicle. Several driving behaviors were recorded directly onto a computer file, including safety-belt use, percentage of times a turn-signal was used, vehicle velocity and following distance (Boyce and Geller, 2002; 2001).

With the advent of instrumented vehicles, field experiments should become increasingly informative. These vehicles are capable of recording a variety of realtime data from inconspicuously mounted sensors and cameras. Drivers may be given various personality assessments before being sent out into various driving conditions. To reduce participant bias, cover stories can initially disguise the true purpose of the research. This type of research holds great promise though it does have some inherent problems such as demand characteristics. However, these are problems for most observational 
research and other error sources such as observer bias would be reduced using this method. Aside from the issue of time consumption during video coding, the most difficult obstacles for most researchers to overcome in this paradigm would be questions of cost and vehicle design.

\subsection{Observing Virtual-World Driving Behaviors}

The final category of study techniques is the use of lab-based driving simulators which avoids most of the problems listed with self-report, driving history records and in-vivo observation. This is another recent hightech development that will advance the study of driver behavior. Ellison-Potter et al. (2001) used a machine called the STISIM Drive Low-Cost Driving Simulator to study aggressive driving. The simulators made by this company range in price from about $\$ 5,000$ $\$ 100,000$ and have such features as: vehicle video monitors arranged around the driver; a rearview mirror screen embedded on the front monitor; full-size steering wheels, brake and accelerator pedals; automatic or manual transmissions; realistic sounds; and active steering columns that give the realistic feel of the car pulling in turns.

With this type of simulator, researchers can realistically manipulate such environmental variables as traffic encountered, number of pedestrians on the street, road types, geography (e.g., rural Vs urban), weather and road conditions, type and number of intersections, speed limit and other road signs and placement of prompts on billboards. In the Ellison-Potter et al. (2001) study, participants either imagined driving in a convertible with the top down where they could be identified by others, or that they had the top up such that others could not identify them (Ellison-Potter et al., 2001). These researchers recorded behaviors such as the number of pedestrians hit, vehicles hit, off-road collisions and the average velocity of the vehicle at fixed intervals.

Bar-Gera and Shinar (2005) conducted a study on the likelihood of drivers to pass other drivers in a simulator program and found that if the vehicle in front moved 3 $\mathrm{km} \mathrm{h}^{-1}$ slower than the simulator driver, the participant would likely attempt to pass the vehicle and in $2 / 3$ of the encounters the simulator driver would pass lead vehicles moving at their pre-passing speed. In $50 \%$ of the encounters, drivers would pass lead vehicles traveling at a faster speed than their own. Bar-Gera and Shinar (2005) considered this latter behavior as an example of driver aggression. Of course, an issue to consider is the real-world generalizability of the experimental situations.
Strayer et al. (2003) used a PatrolSim driving simulator (manufactured by GE Capital I-Sim) to study the use of cellular phones while driving. They concluded that cellular phone conversations caused inattention to driving tasks, which in turn increased the probability of a vehicle crash. Their data suggested, in contrast to popular opinion, that hands-free cellular phones also posed some significant dangers to drivers. While the scenario used in the Strayer et al. (2003) study was rather contrived (i.e., following a single vehicle that randomly braked, in a single lane over many miles), virtual situations could be expanded to cover a variety of circumstances.

Drews et al. (2008) also used a driving simulator to determine whether or not cell phone use impairs driving ability and found that, of all the conditions they used (conversing on a cell phone, conversing with a passenger and driving without conversational distraction), the cell phone use condition produced the highest number of driving errors.

In fact, simulators have been used with increasing frequency to look at the effects of phone use while driving on performance. Recently, researchers did a meta-analysis of cell phone studies and of their set of 33 studies which met inclusion criteria, $17(52 \%)$ were conducted using a driving simulator (Caird et al., 2008). Obviously, there are clear advantages in distracting drivers in safe settings such as simulators and systematic and controlled manipulations are easily achieved. Plus, all manner of driver distractions can be tested and the effects on performance detriments can be precisely calculated.

Simulators have obvious limitations in that they are laboratory-based and not real. They also range in price from a few thousand dollars to well over \$1 million. However, the increased use of driving simulators will produce dangerous driving research with high reliability and internal validity. Within the realm of virtual reality, advances are being made which will soon produce machines capable of all manner of scenario definition, highly realistic driving conditions and potentially, exceedingly valid and generalizable research results. Driving simulators enable researchers to study all kinds of dangerous driving (e.g., driving while intoxicated, drowsy driving and distracted driving) which would not be ethical to study in real-world observational studies. It is refreshing to think that these technological advances are only in their relative infancy and will likely offer much to the scientific study of driving in the immediate and distant future.

\section{CONCLUSION}

The purpose of this study was to review a variety of methods for studying driving behavior in an effort to 
encourage and enable others to develop original driving research and/or extend previous study in this domain. We also remarked on the problem of the lack of consistent and clear conceptual topics and operational definitions and noted the need for theoretical underpinnings to dangerous driving research. While not exhaustive, our review is relatively comprehensive and thus offers a glimpse into the techniques currently used in the study of aggressive and other types of dangerous driving. While the primary focus was on aggressive driving, the methods described are applicable to a wide variety of driving scenarios or issues. The only limitations to the application and/or broadening of the techniques described are those of the researcher's creativity and financial resources. The recent use of driving diaries, cell phone interviews, simulated driving and instrumented vehicles, clearly demonstrate creativity in design.

Dangerous driving is a ubiquitous crisis and worth investigating in all its manifestations, under all plausible conditions. Dangerous driving is the cause of an overwhelming amount of problems in public health and economic areas. Advancing the understanding of the underlying causes and maintenance factors involved in all types of dangerous driving and fostering their amelioration, is of crucial importance and should be reflected in our national and international research agendas.

\section{REFERENCES}

Bar-Gera, H. and D. Shinar, 2005. The tendency of drivers to pass other vehicles. Transportation Res. Part F, 8: 429-439. DOI: 10.1016/j.trf.2005.06.001

Boyce, T.E. and E.S. Geller, 2001. A technology to measure multiple driving behaviors without selfreport or participant reactivity. J. Appl. Behav. Anal., 34: 39-55. PMID: 11317986

Boyce, T.E. and E.S. Geller, 2002. An instrumented vehicle assessment of problem behavior and driving style: Do younger males really take more risks. Accid. Anal. Prev., 34: 51-64. PMID: 11789575

Caird, J.K., C.R. Willness, P. Steel and C. Scialfa, 2008. A meta-analysis of the effects of cell phones on driver performance. Accid. Anal. Prev., 40: 12821293. PMID: 18606257

Cavaiola, A.A., D.B. Strohmetz and S.D. Abreo, 2007. Characteristics of DUI recidivists: A 12-year followup study of first time DUI offenders. Addict. Behav., 32: 855-861. PMID: 16876960
CDCP, 2011. Injury Prevention and Control: Motor Vehicle Safety. World Wide Web.

Chen, C.F. and C.W. Chen, 2011. Speeding for fun? Exploring the speeding behavior of riders of heavy motorcycles using the theory of planned behavior and psychological flow theory. Accid. Anal. Prev., 43: 983-990. DOI: 10.1016/j.aap.2010.11.025

Cherpitel, C.J. and J. Bond, 2003. DUI recidivism: A comparison of Mexican Americans and whites in a northern California county. Addict. Behav., 28: 963969. PMID: 12788268

Crowne, D.P. and D. Marlow, 1960. A new scale of social desirability independent of psychopathology. J. Consult. Psychol., 24: 349-354. PMID: 13813058

Deffenbacher, J.L., 2008. Anger, aggression and risky behavior on the road: A preliminary study of urban and rural differences. J. Appl. Psychol., 38: 22-36.

DePasquale, J.P., E.S. Geller, S.W. Clarke and L.C. Littleton, 2001. Measuring road rage: Development of the propensity for angry driving scale. J. Safety Res., 32: 1-16. DOI: 10.1016/S0022-4375(00)00050-5

DeYoung, D.J., 2002. An evaluation of the implementation of ignition interlock in California. J. Safety Res., 33: 473-482. PMID: 12429104

Doob, A.N. and A.E. Gross, 1968. Status of frustrator as an inhibitor of horn-honking responses. J. Soc. Psychol., 76: 213-218.

Drews, F.A., M. Pasupathi and D.L. Strayer, 2008. Passenger and cell phone conversations in simulated driving. J. Exp . Psychol. Appl., 14: 392-400. DOI: 10.1037/a0013119

Dula, C.S. and E.S. Geller, 2004. Risky, aggressive, or emotional driving: Addressing the need for consistent communication in research. J. Safety Res., 34: 559566. DOI: 10.1016/j.jsr.2003.03.004

Dula, C.S. and E.S. Geller, 2007. Creating a total safety traffic culture. Traffic Safety Culture in the United States: The Journey Forward. American Automobile Association Foundation for Traffic Safety.

Dula, C.S. and M.E. Ballard, 2003. Development and evaluation of a measure of dangerous, aggressive, negative emotional and risky driving. J. Applied. Soc. Psychol., 33: 263-282. DOI: 10.1111/j.15591816.2003.tb01896.x

Dula, C.S., E.S. Geller and F.L. Chumney, 2011. A social-cognitive model of driver aggression: Taking situations and individual differences into account. Curr. Psychol.: A J. Diverse Perspectives Diverse Psychol. Issues, 30: 324-334. DOI: 10.1007/s12144011-9120-3 
Elliot, M.R., P.F. Waller, T.E. Raghunathan, J.T. Shope and R.J.A. Little, 2000. Persistence of violation and crash behavior over time. J. Safety Res., 31: 229-242.

Elliott, M.A., 2010. Predicting motorcyclists' intentions to speed: Effects of selected cognitions from the theory of planned behaviour, self-identity and social identity. Accid. Anal. Prev., 42: 718-725. DOI: 10.1016/j.aap.2009.10.021

Ellison-Potter, P., P. Bell and J. Deffenbacher, 2001. The effects of trait driving anger, anonymity and aggressive stimuli on aggressive driving behavior. J. Appl. Soc. Psychol., 31: 431-443. DOI: 10.1111/j.1559-1816.2001.tb00204.x

Ellwanger, S.J., 2007. Strain, attribution and traffic delinquency among young drivers measuring and testing general strain theory in the context of driving. Crime Delinquency, 53: 523-551. DOI: 10.1177/0011128706295991

Erwin, W.J. and L.A. Wheelright, 2002. Improving mail survey response rates through the use of a monetary incentive. J. Mental Health Counsel., 24: 247-255.

Factor, R., D. Mahalel and G. Yair, 2007. The social accident: A theoretical model and a research agenda for studying the influence of social and cultural characteristics on motor vehicle accidents. Accid. Anal. Prev., 39: 914-921. DOI: 10.1016/j.aap.2006.12.015

Felson, D.T., R.C. Lawrence, M.C. Hochberg, T. McAlindon and P.A. Dieppe et al., 2000. Osteoarthritis: New insights. Part 2: Treatment approaches. Annals Internal Med., 133: 726-737.

Ferguson, S.A., A.F. Williams, J.F. Chapline, D.W. Reinfurt and D.M.D. Leonardis, 2001. Relationship of parent driving records to the driving records of their children. Accid. Anal. Prev., 33: 229-334. PMID: 11204894

Ferrante, A.M., D.L. Rosman and Y. Marom, 2001. Novice drink drivers, recidivism and crash involvement. Accid. Anal. Prev., 33: 221-227. PMID: 11204893

Geller, B., B. Zimerman, M. Williams, M.P. DelBello and K. Bolhofner et al., 2002. DSM-IV mania symptoms in a prepubertal and early adolescent bipolar disorder phenotype compared to attentiondeficit hyperactive and normal controls. J. Child Adolescent Psychopharmacol., 12: 11-25. DOI: 10.1089/10445460252943533

Geller, E.S., 1996. The truth about safety incentives. Profess. Safety, 41: 34-39.
Geller, E.S., 1998. Applications of Behavior Analysis to Prevent Injuries from Vehicle Crashes. 2nd Edn., Cambridge Center for Behavioral Studies. Cambridge, MA., ISBN-10: 1881317080, pp: 160.

Gore-Felton, C., C. Koopman, E. Bridges, C. Thoresen and D. Spiegel, 2002. An example of maximizing survey return rates methodological issues for health professionals. Evaluation Health Professions, 25: 152-168. DOI: 10.1177/01678702025002002

Gulian, E., G. Matthews, A.I. Glendon, D.R. Davies and L.M. Debney, 1989. Dimensions of driver stress. Ergonomics, 32: 585-602. DOI: $10.1080 / 00140138908966134$

Hatfield, J., R. Fernandes, G. Faunce and R.F.S. Job, 2008. An implicit non-self-report measure of attitudes to speeding: Development and validation. Accid. Anal. Prev., 40: 616-627. DOI: 10.1016/j.aap.2007.08.020

Helgeson, J.G., K.E. Voss and W.D. Terpening, 2002. Determinants of mail-survey response: Survey design factors and respondent factors. Psychol. Market., 19: 303-328. DOI: 10.1002/mar.1054

Hennessy, D.A. and D.L. Wiesenthal, 1999. Traffic congestion, driver stress and driver aggression. Aggressive Behav., 25: 409-423. DOI: 10.1002/(SICI)1098-2337(1999)25:6<409::AID$\mathrm{AB} 2>3.0 . \mathrm{CO} ; 2-0$

Houston, J.M., J.A. Johnson, A.N. Skinner and M.V. Clayton, 2006. Assessing aggressive driving: Comparing four self-report measures. North Am. J. Psychol., 8: 301-306.

James, L. and D. Nahl, 2000. Road Rage and Aggressive Driving: Steering Clear of Highway Warfare. 1st Edn., Prometheus Books, Amherst, New York, ISBN-10: 1573928461, pp: 298.

Joint, M., 1995. Road rage. AAA foundation for traffic safety.

Jones, B., 1997. Age, gender and the effectiveness of high-threat letters: An analysis of Oregon's driver improvement advisory letters. Accid. Anal. Prev., 29: 225-234. DOI: 10.1016/S0001-4575(96)00076-0

Kenhove, P.V., K. Wijnen and K.D. Wulf, 2002. The influence of topic involvement on mail-survey response behavior. Psychol. Market., 19: 293-301. DOI: $10.1002 /$ mar.1053

Kposowa, A.J. and K.D. Breault, 2009. Motor vehicle deaths among men: Marital status, gender and social integration. Int. J. Men's Health, 8: 129-142. DOI: 10.3149/jmh.0802.129 
Lajunen, T. and D. Parker, 2001. Are aggressive people aggressive drivers? A study of the relationship between self-reported general aggressiveness, driver anger and aggressive driving. Accid. Anal. Prev., 33: 243-255. PMID: 11204896

Lajunen, T., A. Corry, H. Summala and L. Hartley, 1997. Impression management and self-deception in traffic behaviour inventories. Personality Individual Differences, 22: 341-353. DOI: 10.1016/S01918869(96)00221-8

Lajunen, T., D. Parker and S. Stradling, 1998. Dimensions of driver anger, aggressive and highway code violations and their mediation by safety orientation in UK drivers. Transportation Research Part F: Traffic Psychol. Behav., 1: 107-121. DOI: 10.1016/S1369-8478(98)00009-6

Loftus, E.F., 1974. Reconstructing memory: The incredible eyewitness. Psychol. Today, 8: 116-119.

Loftus, E.F., 2003. Make-believe memories. Am. Psychol., 58: 867-873. PMID: 14609374

Lonero, L.P., 2000. A preliminary heuristic model of aggressive behaviour in drivers. Aggressive Driving Issues Conference.

Lourens, P.F., 1990. Theoretical perspectives on error analysis and traffic behaviour. Ergonomics, 33: 12511263. DOI: $10.1080 / 00140139008925330$

Ludwig, T.D. and E.S. Geller, 1997. Assigned versus participative goal setting and response generalization: Managing injury control among professional pizza deliverers. J. Appl. Psychol., 82: 253-261. PMID: 9109283

Ludwig, T.D. and E.S. Geller, 1999. Behavioral impact of a corporate driving policy undesirable side-effects reflect countercontrol. J. Org. Behav. Manage., 19: 25-34. Preview Buy now DOI: 10.1300/J075v19n02_03

Marlow, D. and D.P. Crowne, 1961. Social desirability and response to perceived situational demands. J. Consult. Psychol., 25: 109-115. PMID: 13766997

Marowitz, L.A., 1998. Predicting DUI recidivism: Blood alcohol concentration and driver record factors. Accid. Anal. Prev., 30: 545-554. PMID: 9666250

Marques, P., A. Tippetts and R.B. Voas, 2003. Comparative and joint prediction of DUI recidivism from alcohol ignition interlock and driver records. J. Stud. Alcohol, 64: 83-92. PMID: 12608487

Mauger, P.A. and D.R. Adkinson, 1980. Interpersonal Behavior Survey (IBS) Manual. Los Angeles: Western Psychological Services.
Millar, M., 2007. The influence of public selfconsciousness and anger on aggressive driving. Personality Individual Diff., 43: 2116-2126. DOI: 10.1016/j.paid.2007.06.037

Nevitt, J.R. and J. Lundak, 2005. Accuracy of selfreports of alcohol offenders in a rural Midwestern county. Psychol. Reports, 96: 511-514. PMID: 15941128

NHTSA, 1998. National survey of speeding and other unsafe driving actions. Driver Attitudes Behav.

NHTSA, 2001. Aggressive driving programs.

NHTSA, 2002. The economic impact of motor vehicle crashes 2000 .

NHTSA, 2010. Traffic Safety Facts: 2009 Data.

NJMVC, 2009. Driver history records.

Oden, L. and J. Price, 1999. Effects of a small monetary incentive and follow-up mailings on return rates of a survey to nurse practitioners. Psychol. Rep., 85: 1154-1156. PMID: 10710970

Parker, D., T. Lajunen and S. Stradling, 1998. Attitudinal predictors of interpersonally aggressive violations on the road. Transp. Res. Part F: Traffic Psychol. Behav., 1: 11-24. DOI: 10.1016/S13698478(98)00002-3

Poulter, D.R., Chapman, P., Bibby, P. A., Clarke, D. D. and Crundall, D., 2008. An application of the theory of planned behaviour to truck driving behaviour and compliance with regulations. Accid. Anal. Prev., 40: 2058-2064. DOI: 10.1016/j.aap.2008.09.002

Rathbone, D.B. and J.C. Huckabee, 1999. Controlling road rage: A literature review and pilot study. The AAA Foundation for Traffic Safety.

Sarkar, S., A. Martineau, M. Emami, M. Khatib and K. Wallace, 2000. Spatial and temporal analyses of the variations in aggressive driving and road rage behaviors observed and reported on San Diego freeways.

Schultheis, M.T., R.J. Matheis, R. Nead and J. DeLuca, 2002. Driving behaviors following brain injury: Selfreport and motor vehicle records. J. Head Trauma Rehabilitation, 17: 38-47. PMID: 11860328

Senn, C.Y., N. Verberg, S. Desmarais and E. Wood, 2000. Sampling the reluctant participant: A randomsample response-rate study of men and sexual coercion. J. Applied Soc. Psychol., 30: 96-105. DOI: 10.1111/j.1559-1816.2000.tb02307.x 
Shinar, D. and R. Compton, 2004. Aggressive driving: An observational study of driver, vehicle and situational variables. Accid. Anal. Prev., 36: 429-437. DOI: $10.1016 / \mathrm{S} 0001-4575(03) 00037-\mathrm{X}$

Shope, J.T., L.J. Molnar, M.R. Elliott and P.F. Waller, 2001. Graduated driver licensing in michiganearly impact on motor vehicle crashes among 16-year-old drivers. J. Am. Med. Assoc., 286: 1593-1598. DOI: $10-1001 /$ pubs

Soderstrom, C.A., M.F. Ballesteros, P.C. Dischinger, T.J. Kerns and R.D. Flint et al., 2001. Alcohol/drug abuse, driving convictions and risk-taking dispositions among trauma center patients. Accid. Anal. Prev., 33: 771-782. PMID: 11579979

Stradling, S.G. and M.L. Meadows, 2000. Highway code and aggressive violations in UK drivers. Proceedings of the Aggressive Driving Issues Conference, Nov. 21-21, World Wide Web.

Strayer, D.L., M.E. Power, W.F. Fagan, S.T.A. Pickett and J. Belnap, 2003. A Classification of ecological boundaries. BioScience, 53: 723-729. 10.1641/00063568(2003)053[0723:ACOEB]2.0.CO;2
Tasca, L., 2000. A review of the literature on aggressive driving research.

Underwood, G., P. Chapman, S. Wright and D. Crundall, 1999. Anger while driving. Transportation Res., 2: 55-68.

Williams, J.H. and E.S. Geller, 2000. Behavior-based intervention for occupational safety: Critical impact of social comparison feedback. J. Safety Res., 31: 135-142. DOI: 10.1016/S0022-4375(00)00030-X

Wills, A.R., B.C. Watson and H.C. Biggs, 2009. An exploratory investigation into safety climate and work-related driving. Work: J. Prevention, Assess. Rehabil, 32: 81-94. DOI: 10.3233/WOR-2009-0818

Wilson, R.J., W. Meckle, S. Wiggins and P.J. Cooper, 2006. Young driver risk in relation to parents' retrospective driving record. J. Safety Res., 37: 325332. PMID: 16996539 